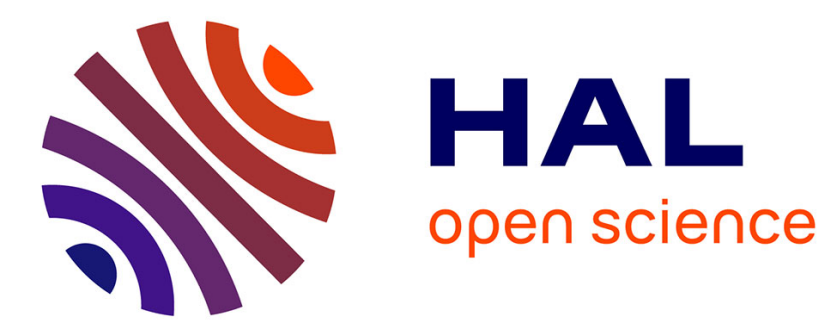

\title{
Noblesse et royauté dans le De rebus Hispaniae (livres 4 à 9)
}

\author{
Georges Martin
}

\section{To cite this version:}

Georges Martin. Noblesse et royauté dans le De rebus Hispaniae (livres 4 à 9). Cahiers de Linguistique et de Civilisation Hispaniques Médiévales, 2003, 26, pp.101-121. halshs-00157631

\section{HAL Id: halshs-00157631 https://shs.hal.science/halshs-00157631}

Submitted on 26 Jun 2007

HAL is a multi-disciplinary open access archive for the deposit and dissemination of scientific research documents, whether they are published or not. The documents may come from teaching and research institutions in France or abroad, or from public or private research centers.
L'archive ouverte pluridisciplinaire HAL, est destinée au dépôt et à la diffusion de documents scientifiques de niveau recherche, publiés ou non, émanant des établissements d'enseignement et de recherche français ou étrangers, des laboratoires publics ou privés. 


\section{Noblesse et royauté dans le De rebus Hispaniae (livres 4 à 9)}

Georges MARTIN

Université Paris-Sorbonne

SIREM

(GDR 2378, CNRS)

Connaissant la haute naissance de Rodrigue Jimenez de Rada, aussi bien du côté paternel et navarrais que du côté maternel et castillan, connaissant la dimension seigneuriale et militaire de son comportement à la tête de l'archevêché de Tolède, connaissant enfin son rôle de conseiller auprès des rois Alphonse VIII et Ferdinand III ainsi que de la reine Bérengère ${ }^{1}$, vous ne serez pas surpris de m'entendre dire qu'il a porté au tout premier plan de son histoire de l'Espagne le groupe nobiliaire et ses relations avec la royauté. Mon étude des rapports de la noblesse et de la couronne se limitera aux livres 4 à 9 du De rebus Hispaniae ${ }^{2}$, segment où se joue toutefois l'essentiel du propos doctrinal de Rodrigue puisqu'il correspond à l'entier de l'histoire des royautés chrétiennes d'Espagne postérieures à la restauration pélagienne -le segment traditionnellement le plus significatif de l'historiographie castillano-léonaise- et que Rodrigue y fait en outre la plus grande place (près de trois livres sur six) aux règnes contemporains ${ }^{3}$.

\section{« Auxilium 》 et « consilium 》 contre « terra 》 et « proventus 》}

Rodrigue a la plus profonde sympathie pour la noblesse. Au sein des catégories sociologiques de son temps, cela se mesure aux rôles qu'il attribue, dans certains épisodes clés, d'un côté, au «vulgus » ou aux « homines plebeii », dont l'opinion est souvent « sotte et changeante $»^{4}$,

\footnotetext{
${ }^{1}$ Sur tous ces points, Georges MARTIN, Les Juges de Castille. Mentalités et discours historique dans l'Espagne médiévale, Annexes des Cahiers de linguistique hispanique médiévale, 6, 1992, p. 251-270.

2 María de los Desamparados CABANES PECOURT (éd.), RODERICUS XIMENIUS DE RADA, Opera, Saragosse : Anubar (Textos medievales, 22), 1985, p. 74-283. Désormais $D R H$.

${ }^{3}$ Règnes d'Alphonse VIII, Henri Ier et Fedinand III : à partir du livre 7 chapitre 15 (DRH, p. 159a).

Sous la minorité d'Alphonse VIII, roi de Castille confronté aux aspirations hégémoniques de son oncle Ferdinand II de León : «Nec etiam fuit locus vel civitas,
} 
qui inclinent volontiers à la sédition ${ }^{5}$, ou dont le conseil -fût-il celui d'un émissaire de Dieu- ne doit être suivi qu'avec la plus grande prudence ${ }^{6}$, et, d'un autre côté, aux «maiores», s'agissant des élites municipales, ou aux «principes » de la noblesse, « sensés», «fidèles » et fiables ${ }^{7}$. Quant aux clercs, Rodrigue semble les préférer nobles et guerriers, tel ce Diègue Vélasquez, moine de Fitero, «homo nobilis, et quondam strenuus in officio militari $»^{8}$, dont la courageuse initiative de secourir Calatrava mal défendue par les Templiers sera à l'origine de la fondation de I'Ordre ${ }^{9}$, tel I'archevêque tolédan Martin le Grand de Pisuerga, honorant d'un seul coup l'Église et ses ancêtres en franchissant le Bétis à la tête des armées royales ${ }^{10}$, tel enfin Rodrigue lui-même, distingué parmi les «autres magnats $\gg$ du royaume lors de la première prise de Quesada ${ }^{11}$, puis conquérant définitivement la place forte en personne à la tête d'une «multitude de gens en armes $»^{12}$.

licet Regem Fernandum praedictis de causis stulta vulgi mobilitas sequeretur, in quibus aliqui saniori et fideliori mente praediti Regi puero non faverent », $D R H, \mathrm{p} .162 \mathrm{a}$.

${ }^{5}$ Après la répression par Ferdinand II de León de la révolte du peuple de Salamanque: « Et sic, maioribus sibi faventibus, quorum sententia principio non potuit praevalere, vim vulgi multitudine faciente, demum experti praesumptionis flagellum, et potentia minorati, nunc suis maioribus et suo Principi pro venia supplicabant, et sic Rex vistor civitatem, ut voluit, subiugavit, maioribus qui sibi faverant, honoratis », ibid., p. 164a.

${ }^{6}$ Préliminaires tactiques de Las Navas de Tolosa : «Cumque hoc consilium nobilis Regis praevaluisset, Deus omnipotens qui negotium speciali pratia dirigebat, misit quemdam hominem plebeium, satis despicabilem et habitu et persona, qui olim in montanis illis pecora paverat, et cuniculorum et leporum ibidem captioni institerat. Is ostendit facilem viam, omnino possibilem, per declivum lateris montis eiusdem; nec oportere ab aspectu hostium occultari, et ipsis videntibus, nec impedire valentibus, venire ad locum pugnae congruum poteramus [...] Sed quia in tanto discrimine tali personae vix credi poterat, duo Principes praecesserunt, Didacus Lupi de Pharo et Garsias Romerii, ut invenirent esse vera quae pastor dixerat, montem quemdam in summitate sui habentem planitiem occuparent $\gg$, ibid., p. 183a-183b.

${ }^{7}$ Voir notes 4, 5 et 6.

${ }^{8} D R H$, p . 158a. Également, p. 158a-158b : « Abbas [...] consensit monacho, olim militi, supplicanti, et accedens ad Regem, petiit Calatravam ».

${ }^{9}$ Ibid., p. 158-159.

10 « Exercitus [Regis Adefonsi] transivit Baetim, et dux eius praesul Toleti. Magnates regni in consiliis praesulis, et exercitus omnis sub praesule dignitatis: nomen eius Martinus Magnus, et genus eius à Pisorica : honor gentis vita eius, et stola eius diadema Ecclesiae », ibid., 170a.Puis: «[...] cingulum eius zelus fidei, et arma eius ad persecutionem blasphemiae. Agmen omne ad nutum illius, sanguis Arabum in conspectu illius. Regio Baetica flammis succenditur, et factum praesulis prosperatur. Processit enim per castra Baeticae, terras et oppida succendendo ; feliciter autem ad propria est reversus $\gg$.

${ }^{11}$ «Sed [Rex] exercitu congregato, assistentibus sibi Roderico Toletano Pontifice et aliis magnatibus regni sui, per Beatiam et Ubetam vastationes exercens, agressus est Caseatam, et captis et interfectis multis Sarracenorum, quia castrum variis impugnationibus erat dirutum, tunc noluit retinere », ibid., p. $201 \mathrm{~b}$.

12 «Tunc Rex Fernandus dedit Caseatam iure hereditario Roderico Archiepiscopo Toletano, quae tamen aliquantulum reparata, à Sarracenis incolis tenebantur. Sed 
Regard de noble - c'est la part originaire, «naturelle », de Rodrigue Jimenez de Rada qui s'exprime ici- porté sur la tripartition du social. Mais aussi et surtout sur l'ordre politique. Les épisodes sont innombrables qui ont charge d'illustrer le poids déterminant de la noblesse sur le sort des rois : menaces de déposition brandies par les «magnates » à l'endroit d'Alphonse le Chaste qui s'apprête à léguer le royaume d'Oviedo à Charlemagne ${ }^{13}$, mise à mort par le « sénatus » d'un Fruela Vermudez au comportement tyrannique ${ }^{14}$, assassinat de l'infant Garsias par les nobles que son père, le comte Sanche, a expulsés «indignanter» de Castille ${ }^{15}$, défaite et mort de Garsias III de Navarre à Atapuerca parce qu'il n'a pas su se gagner I'《animus » des siens ${ }^{16}$, et, à la mort sans descendance d'Alphonse le Batailleur, le trop « superbe » Pierre Atarès écarté du trône au bénéfice de Ramire le Moine par les «nobiles» aragonais ${ }^{17}$. Ou bien au contraire: couronnement solennel d'Ordoño II avec I' « accord » unanime des «principes » et des « magnates $»^{18}$, Juges de Castille élus à

Rodericus Archiepiscopus, evolutis à donatione tribus mensibus, exercitu congregato, ivit contra Caseatam cum multitudine armatorum, et expulsis Mauris qui ruinas oppidi reparabant, illud retinuit et ad honorem Regis qui illud dederat Ecclesiae Toletanae, custodivit hactenus », ibid., p. 204b-205a.

${ }_{13}$ Ibid., p. 83a : «Post nunciorum autem reditum innotuit legatio magnatibus Aldefonsi, qui aequanimiter non ferentes, suaserunt Regi cum instantia, ut quod mandaverat, revocaret, alioquin ipsum à regno expellerent, et pacta eius nullatenus observarent, et sibi de alieno domino providerent $\gg$;

${ }^{14}$ Ibid., p. 89b : «Inter hac autem, dum praedictus Froila plus tyrannice, quam regaliter se haberet, Oveti interficitur à senatu ».

${ }^{15}$ Ibid., p. 115b : « Tunc quidam milites de rregno Legionis cum praedictis filiis Vegilae ad Sarracenos transfugae, eo quod à Comite Sancio indignanter recesserant à Castella, proditione tractata, Infantem Garsiam annorum tredecim occiderunt ».

${ }^{16} C^{\prime}$ est même un des chevaliers qu'il a particulièrement lésés qui met fin aux jours du roi : «Cumque mutuis caedibus hinc inde exercitus se impeterent, coepit praevalere exercitus Castellanus, eo quod numero et potentia excedebat, et Rex Garsias suorum animos non habebat » et «Tunc quidam milites [...] Regis Garsiae acies cum duobus militibus qui $a b$ eo recesserant, impetu irrumpentes, ad Regis aciem pervenerunt, et alter militum qui ab eo recesserat, dicitur eum lancea perfodisse » (ibid., p. 124b ).

${ }^{17}$ Ibid., p. 118 : « Unde et quemdam nobilem qui dicebatur Petrus Tarasiae, volebant Regi mortuo subrogare ; et quia ille minus provide se gerebat, coepit de futuro nomine se insolere, et spei, non rei dominio superbire, et nobiles dedignari. Unde duo magnates, scilicet Petrus Titionis de Catherecta, et Peregrinus de castello Acioli, cum essent nobiles et potentes, et vellent fidelitatem naturali domino custodire, plurimum animos à primo proposito revocarunt, et ut Ranimirum monachum à monasterio evocarent, vigilanti studio procurarunt. [...] In eadem autem curia, procurantibus dictis magnatibus, fuit promotio Petri Tarasiae impedita, et res dilata usque ad curiam Montionis. Cumque in Montione iterum convenissent, potiorum consilium hoc firmavit, ut Ranimirum monachum fratri mortuo subrogarent : et eductum de monasterio apud Oscam in regni solio collocarunt ».

${ }_{18}$ Ibid., p. 96a : « [...] In eadem Ecclesia communi favore principum et magnatum à duodecim Pontificibus fuit diademate insignitus ». 
leur tête par les «nobiles» de Bardulie ${ }^{19}$, Vermude, futur roi de León, porté d'abord à la royauté par les «comites» galiciens qu'avait «provoqués »I' « insolentia » de Ramire III $^{20}$, Garsias Ramirez, montant sur le trône de Navarre par l'entremise des «barones » Aznar de Oteiza et Fortuné Iñiguez de Leet $^{21}$, Gomez de Manzanedo et Gutierre Fernandez de Castro travaillant au couronnement d'Alphonse VII ${ }^{22}$, et, plus près de Rodrigue, Alphonse VIII enfant résistant aux assauts de Ferdinand II de León et conservant sa couronne grâce à l'appui des comtes de Lara et d'autres nombreux «magnates $»^{23}$. Mais que les Lara faillissent sous la minorité d'Henri Ier, fondamentalement, du reste, en s'en prenant aux élites nobiliaires, municipales et ecclésiastiques, ce qui aggrave leur cas, voici toujours d'autres «magnates», d'autres «nobiles» pour se regrouper autour de la reine Bérengère et oeuvrer au salut du royaume ${ }^{24}$. Dans la chute, l'émergence ou la stabilité des rois, la présence nobiliaire est constante.

19 Ibid., p. 97 : «Eisdem [Froilae] diebus nobiles Barduliae [...] sibi et posteris providerunt, et duos milites [...] elegerunt, quos et iudices statuerunt, ut dissenssiones patriae et querelantium causae eorum iudicio sopirentur $\gg$.

${ }^{20}$ Ibid., p. 105b : «Cumque esset puer [Rex Ranimirus], nec ad discretionem aetatis venisset, stultis actibus coepit Comites Gallaeci provocare, iam à consilio matris et amitae alienus. Cumque Gallaeci non possent eius insolentiam tolerare, quemdam Veremundum filium Regis Ordonii super se Regem in sede beati Iacobi creaverunt » (et p. 105b-106a : «Mortuo itaque Ranimiro, Veremundus filius Regis Ordonii veniens Legionem, ab omnibus suscipitur, et ad regni gloriam promovetur »).

${ }^{21}$ Ibid., p. 114a : «Unde cum post mortem Petri et Adefonsi Regum Aragoniae qui sine filiis decesserunt, regnum Navarrae diversis studiis traheretur, Navarri Garsiam Ranimiri de quo diximus, missis duobus Baronibus, Guillelmo Acenarii de Oteica, et Fortunio Enechonis de Leet, clanculo à Montionis curia evocarunt, et eum sibi in Regem et Principem elegerunt $\gg$.

${ }^{22}$ Ibid., p. 149b-150a : «Verum timentes ne res ad effectum casu aliquo perveniret, Gometho de Maceneto et Guterrius Fernandi de Castro prae omnibus institerunt, ut Aldefonsum Reginae filium et Comitis Raimundi, quem à tempore avi in Gallaecia nutriebant, ad regni fastigium evocarent. Qui favore omnium evocatus, in regni solio collocatur ».

${ }^{23}$ Ibid., p. 162a : «Itaque puerorum ludicra vir mente transcendens, et bella plurima contra patruuam decenter exercuit, et munitiones plurimas immeriti perditas merito recuperavit, faventibus sibi Amalrico et Nunio Comitibus, et plurimis magnatibus, qui toto tempore vitae suae ei inseparabiliter et fideliter adhaeserunt, qui etiam eum propriis humeris et brachiis nutrierunt ».

${ }^{24}$ Ibid., p. 193a : «Qui [Comes Alvarus] cum Gundisalvo Roderici et fratribus suis tunc sibi faventibus in continenti Burgis egrediens, coepit exterminia procurare, magnos humiliare, et vulgi divites exhaurire, religiones et Ecclesias ancillare, et decimarum tertias quae ad Ecclesiarum fabricas pertinebant, coepit similiter infiscare », mais $p$. 193b : « Verum cum apud Vallem oleti curiam celebrassent magnates alii, Lupus Didaci de Pharo, Gonsalvus Roderici et fratres eius, Rodericus Roderici, et Alvarus Didaci de Camberis, Alfonsus Tellii de Menesis, et alii nobiles, regni exterminio condolentes, curaverunt tantis cladibus obviare et Reginae Berengariaeprudentiam adeuntes, humiliter supplicarunt, ut regni miseriis condoloret ». 
Mais l'intervention de la noblesse n'est pas seulement sensible en ces grands moments de l'histoire des royautés. Les nobles s'intéressent aussi à des faits de moindre importance, jamais sans conséquence toutefois, touchant aux destinées du royaume ou aux choses de l'Eglise. Ils n'ignorent rien des stratégies matrimoniales et les «magnates » léonais « préoccupés par le déclin de la patrie » dû aux guerres avec Sanche le Grand de Navarre, peuvent ainsi amener Vermude III à marier sa sœur avec l'infant navarrais Ferdinand ${ }^{25}$. On voit également le groupe indiscriminé de la «militia » intervenir, aux côtés du «clerus» et cette fois surtout du «populus», dans la question du passage de la liturgie mozarabe ou «tolédane » au rite romain ou «français », même si à cette occasion -Rodrigue, à l'évidence, le regrette- la « militia » n'a pas gain de cause $^{26}$. L'étroite collaboration entre noblesse et royauté s'exprime enfin, tout au long du récit, par une scénographie de fond où se succèdent les délibération du roi avec ses $《$ magnates $\gg^{27}$, les exhortations à bien faire des nobles précepteurs («nutricii ») à leurs disciples royaux ${ }^{28}$, les évocations ou les apparitions du roi en majesté entouré de ses « comites », « magnates » et autres « milites $»^{29}$.

25 Ibid., p. 122a : «Magnates autem detrimentum patriae attendentes, Regem Veremundum suasione et consilio induxerunt, ut sororem suam Sanciam, valde pulchram virginem, daret Fernando filio Regis Sancii in uxorem ».

${ }^{26}$ Après I'ordalie d'un combat singulier favorable au champion du rite tolédan, puis celle, toujours favorable à celui-ci, d'une épreuve du feu, le roi ordonne l'application du « rite français ». Rodrigue conclut alors : «Et tunc, cunctis flentibus et dolentibus, inolevit proverbium : Quo volunt Reges, vadunt leges », ibid., p. 139b (voir également p. 139a : « [...] fuit diutus altercatum, clero, militia, et populo firmiter resistentibus, ne officium mutaretur», «Cumque duo milites fuissent electi, unus à Rege, qui pro officio Gallicano, alter à militia et populis, qui pro Toletano pariter decertarent »).

${ }^{27}$ Ibid., p. 203 a : « [Rex Fernandus] habito suorum magnatum consilio, inde recessit 》; passim

${ }^{28}$ Ibid., p. $112 \mathrm{~b}$ : « Nutricius autem eius cum esset nobilis et abundans, semper eum consiliis et auxiliis ad magnalia provocabat » (cas de Sanche Arbarca de Navarre) ; p. 124b : «Ad hoc nutricius eius, qui eum ab infantia nutrierat, vir prudens, et bonus, strenuus, et fidelis, sinceris lacrimis consulebat, ut et petitis annueret, et sibi suorum animos complanaret » (cas de Garsias III de Navarre).

${ }^{29}$ Ibid., p. 151 a : « [...] fuit vir bonus, largus, strenuus, mansuetus. Cuius tempora viris optimis, Comitibus, magnatibus, et aliis strenuis militibus abundarunt, cum quibus magna et ardua attentavit, et felici exitu consummavit» (évocation historique par anticipation du règne d'Alphonse VII) ; p. 154b : «Quod praesentiens Imperator, Burgis occurrit turba herilium procerum comitatus » (Alphonse VII accueille Louis VII de France à Burgos) ; p. 172a : « [...] et Regi Legionis vallem Oleti cum suis magnatibus venienti dedit praedictam filiam in uxorem » (Alphonse IX de León se présente à Valladolid pour recevoir comme épouse la fille d'Alphonse VIII de Castille, Bérengère) ; p. 177b : « Aderat in urbe regia cum nobili Rege magnatum suorum generosa societas, nobilitate, strenuitate, et multitudine approbanda, quos sic et morum elegantia, et curialitatis praerogativa, et strenuitatis supereminentia, venustaverat, ut et in oculis hostium non 
Rodrigue maîtrise parfaitement le vocabulaire de cette solidarité politique qui, du côté de la noblesse, s'exprime par l'« auxilium » et le «consilium $»^{30}$. Mais l'enseignement, comme l'œuvre qui le porte, s'adresse d'abord au roi. À ce titre, la mythologie politique que nous avons vu se déployer jusqu'ici, et qui impose au récit historique la structure profonde d'un empilement de cellules narratives sémantiquement homologues, le cède quelquefois au discours qui déclare le sens. Voici, par exemple, les fortes paroles lancées par Rodrigue luimême à Alphonse VIII sur la scène de Las Navas de Tolosa une fois la victoire acquise :

«Gardez en mémoire la grâce de Dieu, qui a suppléé à toutes vos insuffisances et a effacé aujourd'hui l'opprobre que vous avez supporté si longtemps. Mais souvenez-vous aussi de vos chevaliers («milites») avec l'aide desquels («quorum auxilio ») vous avez atteint si grande gloire $»^{31}$.

Et voici l'édification plus doctrinale, impliquant une pièce de l'imaginaire historique espagnol aussi importante que le processus de Reconquête, de Ferdinand II de León par un autre grand Castillan, le roi Sanche III, son frère :

«Puisque notre père [Alphonse VII I'Empereur] a divisé son royaume entre nous, nous sommes tenus de partager la terre («terra») et son produit («proventus») avec les grands («magnates »), vous avec les vôtres, moi avec les miens, puisque aussi bien c'est avec leur aide («quorum auxilio ») que nos ancêtres ont recouvré la terre perdue et repoussé les Arabes $\gg^{32}$.

La terre que gouvernent les rois, reconquise par la noblesse, doit d'une façon ou d'une autre faire retour à celle-ci, lui revenir. Auxilium + consilium $=$ terra + proventus, telle est l'équation d'une réciprocité

solum terribiles, verum digni honoribus apparerent» (Alphonse VIII rassemble ses forces à Tolède avant la campagne qui aboutira à l'affrontement de Las Navas).

${ }^{30}$ Voir notes 25,27 et 28 de cet article.

$31 D R H$, p. 187a : «Dei, quae omnes defectus in vobis supplevit, et opprobrium aliquandiu toleratum hodie relevavit. Estote etiam memor vestrorum militum, quorum auxilio ad tantam gloriam pervenistis ».

${ }^{32}$ Ibid., p. 157b : « [...] Sed cum pater noster regnum nobis diviserit, et vos vestris, et ego meis et proventus et terram tenemur magnatibus impartiri, quorum auxilio patres nostri terram perditam habuerunt, et Arabes repulerunt ». 
nécessaire à l'harmonie des rapports entre noblesse et royauté. C'est bien en noble que s'exprime Rodrigue Jimenez de Rada, le plus tranquillement du monde ou, si l'on veut, de la façon la plus crue.

\section{« Fidelitas 》 contre « largitas 》}

Ce soubassement contractuel affleure plus d'une fois dans sa matérialité dénudée mais, le plus souvent, des valeurs ressortissant à une forme d'éthique politique, l'enrobent. Du bon roi ou du bon seigneur, Rodrigue dira volontiers qu'il est «mansuetus $»^{33}$, «affabilis $»^{34}$, 《amabilis $»^{35}$, « benignus $»^{36}$, « hilaris $»^{37}$, « modestus $»^{38}$. Il le montrera mêlé à ses troupes, aux chevaliers comme aux piétons ${ }^{39}$, ou participant joyeusement aux jeux guerriers ${ }^{40}$. Généreux surtout. Car c'est bien la «largitas», une largesse que I'on souhaiterait sans limite, qui caractérise avant tout le bon souverain. «Largitas » de Garsias Iñiguez ${ }^{41}$, de Garsias le Tremblant distribuant à ses chevaliers «tout ce qu'il pouvait obtenir $\gg^{42}$, d'Alphonse VII I'Empereur ${ }^{43}$, de Ramire le Moine, «liberalis » au point d'offrir à ses chevaliers «presque tous les domaines et les

\footnotetext{
${ }^{33}$ Ibid., p. 115a : «Comitatum et regnum laudabiliter gubernavit, omnibus mansuetus, iustus, pacificus, et modestus » (Thibaud de Champagne, roi de Navarre).

${ }^{34}$ Fruela Ier tue son frère Vimara «propriis manibus » parce qu'il a cette redoutable qualité : «Cumque frater eius Vimaranus esset pulcher, strenuus, et affabilis, $a b$ omnibus amabatur », ibid., p. $80 \mathrm{~b}$.

${ }^{35}$ Ibid., p. 79b : « omnibus se amabilem exiberat » (Alphonse le Chaste, roi d'Oviedo).

${ }^{36}$ Ibid., p. 113b : « Hic bonus, pius, et largus, strenuus, et benignus » (Garsias le Tremblant, roi de Navarre).

37 Ibid., p. 178b : « [...] tedium in virtutem mutaret, cum vultu hilari taedium superaret»5Alphonse VIII de Castille). C'est une qualité que possède aussi AlMansour : «Almanzor autem cum esset prudens, strenuus, hilaris », p. 107b.

38 Thibaud de Champagne, entre autres, ibid., p. 115a (cf. note 33). La « modestia » est une des qualités majeures de la reine Bérengère. À son propos, Rodrigue parle de « pudica modestia » (ibid., p. 175b), de « pudor modestiae » (ibid., p. 196b). Est en revanche censurée la « superbia » de Garsias III de Navarre (ibid., p. 124a) ou du candidat au trône Pierre Atarès (ibid., p. 118a),

${ }^{39}$ Ibid., p. 113a : «Et quia habebat populos agiles, et in spiculorum actibus expeditus, ut eos ad bella et infestationes Arabum amplius provocaret, interdum cum militibus studio militari, interdum cum peditibus officio peditali, semper tamen proelis fidei insistebat» (Sanche Ier Abarca de Navarre); p. 113b : « [...] quia imitator patris, interdum se peditum phalangibus immiscebat, peditans aggregatim, et etiam calceamentis similibus utebatur » (Garsias le Tremblant, fils du précédent).

${ }^{40}$ Ibid., p. 178b : « [...] curiali applausu fastibus militaribus occurrebat » (Alphonse VIII de Castille).

${ }^{41}$ Ibid., p. 112 a : « vir largus et strenuus».

${ }^{42}$ Ibid., p. 113b : « Hic bonus, pius, et largus, strenuus, et benignus, et quidquid habere poterat, militibus erogabat ».

${ }^{43}$ Ibid., p. 151a : « [...] fuit vir bonus, largus, strenuus, mansuetus ».
} 
châteaux de la couronne ${ }^{44}$, d'Alphonse II d'Aragon, «liberalitatis satis amator $\gg^{45}$, d'Alphonse de Provence, son fils ${ }^{46}$, de Pierre Ier d'Aragon, le plus généreux de tous, peut-être, puisqu'«il distribuait avec libéralité tout l'argent qu'il pouvait obtenir au point d'engager villes et châteaux pour que sa main, accoutumée à toujours donner se fût jamais étrangère à la prodigalité $\gg^{47}$, de Sanche III de Castille ${ }^{48}$, largesse extrême, également, de Ferdinand II de León qui ne possédait presque rien en propre $^{49}$, de Thibaud de Champagne en croisade, couvrant les frais des chevaliers indigents, même ceux qui n'étaient pas à sa charge, et payant la rançon des captifs ${ }^{50}$, largesse enfin d'Alphonse VIII à la veille de la bataille de Las Navas de Tolosa, à laquelle Rodrigue consacre un long dithyrambe chiffrés1. Le critère passe les frontières ethniques et

${ }^{44}$ Ibid., p. $118 \mathrm{~b}:$ « [...] liberalis, adeo quod fere omnes villas et castra regalia militibus est largitus 》.

${ }^{45}$ Ibid., p. 119a : « Hic fuit strenuus et liberalitatis satis amator ».

${ }^{46}$ Ibid., p. 119a : « Hic fuit bonus, strenuus, atque largus ».

${ }^{47}$ Ibid., p. 119b: « Hic fuit strenuus, curialis, et largus, et undecumque pecunias habere poterat, liberaliter erogabat, adeo quod interdum castra et municipia creditoribus obligabat, ne manus solita semper dare, invenitur à largitionibus aliena ».

${ }^{48}$ Ibid., p. 157a : «Quid de moribus eius, de strenuitate in hostes, de liberalitate in omnes... dicam ? »

${ }^{49}$ Ibid., p. 163b : «Fuit autem Rex iste Fernandus pius, hilaris, liberalis, strenuus, benignus, et in proelis fortunatus, erga religiones et Ecclesias sic devotus, ut eis fere omnia regalia largiretur, quae tamen postea filius eius revocavit; et adeo comunis omnibus habebatur, quod, tamquam regularis, in mobilibus fere proprium non habebat ».

${ }^{50}$ Ibid., p. 115a : « [...] ivit in subsidium Terrae Sanctae, et loca plurima acquisivit, quae christianae restituit potestati, ibique omnibus militibus indigentibus, etiam iis qui in expensis eius non iverant, usque ad reditum in sumptibus satisfecit, plerosque milites quos Agarenorum versutia captivaverat, pactis et pecuniis liberavit ».

${ }^{51}$ Ibid., p. 179a-b : «De largitate autem eius, quis loqui praesumeret ? Cum id in ipso modicum fuerit, quod in aliis vix poterat reperiri. Sic enim ab infantia largitatem servavit, ut oblivisci non potuerit quo de matris utero secum traxit. Sic omnia largitatis suae privilegio confirmavit, ut ore omnium promulgata sententia, omnibus munificis silentio imposito, praerogativam munificentiae sententialiter obtineret. Et licet magnis magnifice distribueret, manum à minoribus non retraxit. Cum enim essent ultramontani plusquam decem

millia equitum, et centum millia peditum, unicuique militi dabantur omni die viginti solidi usuales, pediti vero quinque solidi : mulieres, parvuli, debiles, et ceteri ad bellum inepti non erant $a b$ hac gratia alieni. Haec erant quae in communi et publice donabantur, praeter donaria privata, quae sui quantitate hunc numerum excedebant, quae magnatibus non diurna distributione, sed potiori summa per nobilis Regis nuncios mittebantur. His muneribus cumulabatur equorum numerosa generositas, parvulorum iucunda varietas, quae omnia tenacitatis curva severitas vultu propitio non poterat intueri. His autem omnibus si iungantur Regibus oblata donaria, suis distributa stipendia, plus modus dantis et hilaritas meruit, quam omnibus emi posset. Et haec omnia, ne gens alienigena expeditionis omnibus indigeret, omnibus tentoria et eorum vehicula est largitus. Addidit etiam gratiam gratie, et cibariorum vehicula cum ceteris necessariis sexaginta millia summas et ultra cum summariis erogavit ». 
religieuses, puisque c'est d'abord à sa générosité qu'Al-Mansour doit ses innombrables victoires ${ }^{52}$ et Al-Mémoun de Tolède, voulant être utile et agréable à Alphonse VI, sait que le mieux est encore de lui donner « de I'or, de l'argent, des chevaux et des armes pour qu'[il puisse] gagner la faveur des siens $\gg^{53}$.

Cette valeur ${ }^{54}$, ancrée dans l'économique, est celle qui, en ce qui concerne la royauté, s'illustre le plus dans le De rebus Hispaniae, même si n'en sont pas absentes des valorisations ressortissant au droit et concernant notamment le statut du groupe nobiliaire. Par exemple, le comte Sanche de Castille, qui était considéré par la tradition historiographique comme «celui qui [avait donné] les bons fors » est ici tenu, plus spécifiquement, pour avoir « renforcé la noblesse des nobles », c'est-à-dire probablement, accru leurs privilèges ou leurs prérogatives ${ }^{55}$. C'est grâce à la «largitas», néanmoins, que l'on mérite le titre de «bouclier des nobles ${ }^{56}$ et que I'on provoque, à sa mort, la « désolation des grands $\gg^{57}$, que I'on gagne, nous l'avons vu, $\mathrm{I}^{\prime}$ «animus» de ses sujets $^{58}$, que I'on éveille, enfin, l'affect amoureux qui forme le ciment du rapport politique dans la société médiévale ${ }^{59}$. «Ab omnibus amabatur » :

\footnotetext{
${ }^{52}$ Ibid., p. 107b : « Almanzor autem cum esset prudens, strenuus, hilaris, atque largus, ita sibi Christianos allicere satagebat, ut Christianos Arabibus ostenderet cariores. Hac benignitate carissimus erat suis, adeo quod omnes ex animo ei serviure pari studio laborabant ».

${ }^{53}$ Ibid., p. 133b : «Nunc autem vade, et accipe regnum tuum, et de meo accipe aurum, argentum, equos, et armas, quibus possis tuorum animos complanare » (Al-Mémoun s'adressant à Alphonse lorsque celui-ci, ayant appris la mort de son frère Sanche II, s'apprête à quitter son hôte pour prendre possession des royaumes de León et de Castille).

${ }^{54}$ La contre-valeur est ici la «cupiditas», reprochée par exemple à Sanche VI de Navarre qui, s'employant à engranger des fonds en terres musulmanes, oublie son royaume et perd Vitoria assiégée par les Castillans ainsi qu'un grand nombre d'autres villes (ibid., p. 172b). À la rapacité du roi de Navarre, qui revient des terres musulmanes « onustus muneribus Agareni, sed exoneratus praedictis omnibus et honore », Rodrigue oppose la « liberalitas » de l'évêque Garsias de Pampelune (ibid.)

${ }^{55}$ Il est vrai que Sanche «tempère » également «la dureté de la servitude parmi les humbles », ibid., p. 111a : « Huic successit in Comitatu Sancius filius eius, vir prudens, iustus, liberalis, strenuus, et benignus, qui nobiles nobilitate potiore donavit, et in minoribus servitutis duritiam temperavit ».

${ }^{56}$ Ibid., p. 157a : « Hic Rex Sancius tanta benignitate pollebat, quod clypeus nobilium dicebatur » (Sanche III de Castille);

57 Ibid., p. 192a : «Et factus est luctus omnium, et desolatio magnatum, necnon et omnium populorum » (mort d'Alphonse VIII de Castille).

${ }^{58}$ Ibid. , p. 107b, 112b, 118b, 124b, 133b, passim.

59 «Le mot pour les dire. Sondage de l'amour comme valeur politique médiévale à travers son emploi dans le Poema de mio Cid», in : Le discours amoureux (Serge SALAÜN, dir.), Service des Publications de I'Université de la Sorbonne Nouvelle (ParisIII), 1986, p. 17-59. Egalement, sous le titre $d^{\prime}$ «Amour (une notion politique) », in :
} 
avec de très légères variantes, la formule vaut pour Alphonse le Catholique $^{60}$, pour Vimara, frère de Fruela Ier $^{61}$, pour Alphonse le Chaste ${ }^{62}$, pour le juge Nuño Rasura ${ }^{63}$, pour Sanche III de Castille ${ }^{64}$, pour Ferdinand, fils aîné d'Alphonse VIII ${ }^{65}$, etc. Bien : nous voyons jusqu'ici Rodrigue adopter le point de vue de la noblesse et adresser à la royauté un enseignement conforme aux attentes du groupe nobiliaire. N'est-il, cependant, aucune valeur propre à celui-ci qui, réciproquement, I'oblige auprès des rois?

$L^{\prime}$ « auxilium », le «consilium», les nobles les prêtent certes au monarque en échange de son «affabilitas» et, surtout, de sa «largitas», laquelle éveille en eux I'«amor» et gagne les «animi ». Mais il est tout de même une valeur qui ne dépend pas entièrement de cette économie contingente, qui lie le noble à son roi par une contrainte nécessaire tenant à l'éthique politique et au droit, en un mot, que Rodrigue emploie du reste volontiers en la circonstance, un « debitum $\gg^{66}$. Une seule, centrale, dont Rodrigue fait véritablement le levier du « devoir faire » politique du noble : la «fidelitas ». Si c'est bien à cause de la sévérité du comte Sanche à leur égard que les Vela vont assassiner son fils, I'infant Garsias, sur ces nobles mus par la vengeance retombe l'opprobre gravissime de la «proditio», tandis que les compagnons de l'infant, sont loués pour leur «fidelitas », même si, aveuglés par elle, ils n'ont pas su prévenir le coup fatal ${ }^{67}$. Voici maintenant, s'affirmant en dépit de l'inconduite d'un Garsias III de Navarre gouverné par la «superbia», coupable de confisquer leurs terres aux nobles et de modifier arbitrairement les lois du royaume ${ }^{68}$, la « fidelitas $»$ exemplaire

Georges MARTIN, Histoires de I'Espagne médiévale. Historiographie, geste, romancero, Annexes des Cahiers de linguistique hispanique médiévale, 11, 1997, p. 169-206.

${ }^{60}$ Ibid., p. 79 a. Et p. 79b : « omnibus se amabilem exibebat ».

${ }^{61}$ Ibid., p. $80 \mathrm{~b}$.

${ }^{62}$ Ibid., p. $86 \mathrm{~b}:$ : amabilis Deo et hominibus $\gg,$.

${ }^{63}$ Ibid., p. 98a : « carus ab omnibus habebatur ».

${ }^{64}$ Ibid., p. 157a.

${ }^{65}$ Ibid., p. $175 a$.

${ }^{66} \mathrm{Cf}$. notes 73, 75, 76, 80, 88 et 109 de cet article.

${ }^{67} D R H$, p. $115 \mathrm{~b}$ : « Tunc quidam milites de regno Legionis cum praedictis filiis Vegilae ad Sarracenos transfugae, eo quod à Comite Sancio indignanter recesserant à Castella, proditione tractata, Infantem Garsiam annorum tredecim occiderunt, Roderico Vegilae ea manu, qua eum de sacro fonte levaverat, gladio feriente. Et proditionem huiusmodi sponsa sua Sancia quae utcumque perceperat, revelarat; sed magnates qui secum aderant, cum essent nobiles et fideles, tantum facinus credere noluerunt ».

${ }^{68}$ Ibid., p. 124 a : « Cum enim praecelleret strenuitate corporis, et virium magnitudine super omnes, adeo ut omnibus praemineret, crudeli superbia grassabatur, et possessiones militum infiscabat, et iura patria immutabat ». 
de son précepteur ${ }^{69}$ à Atapuerca, lequel, voyant le roi aller, sans $I^{\prime}$ « animus » des siens, à la défaite et à la mort, se lance sans protection dans la bataille pour n'être pas témoin de cette triste fin $^{70}$. La liste des exemples, ici encore, serait fastidieuse : «fidelitas » des Ansurez, qui accompagnent Alphonse VI dans son exil tolédan et veillent constamment à ses intérêts ${ }^{71}$, « fidelitas », dans le déchirement des époux royaux, des tenants aragonais des forteresses castillanes à Alphonse le Batailleur d'Aragon $^{72}$ et des tenants castillans à la reine Urraque de Castille $^{73}$, « fidelitas » capitale des Lara et d'autres «magnats et «milites » à Alphonse VIII de Castille aux premiers temps de sa minorité ${ }^{74}$, « fidelitas » également décisive, dans les mêmes circonstances, des Haro et des lignages de la Terre de Campos à Bérengère et au jeune Henri $\mathrm{Ier}^{75}$, «fidelitas » des «potiores »d'Estrémadure à la reine Bérengère

${ }^{69}$ Ibid., p. 124 b : « Ad hoc nutricius eius, qui eum ab infantia nutrierat, vir prudens, et bonus, strenuus, et fidelis, sinceris lacrimis consulebat, ut et petitis annueret, et sibi suorum animos complanaret ».

${ }^{70}$ Ibid., p. $124 \mathrm{~b}$ : « Tunc ille nutricius inquit: 'Intelligo quod hodie victus et ingloriosus morieris, sed ego praemoriar, ne te videam morientem quem tanto studio enutrivi'. Cumque se exercitus circumspicerent, et ad certamen undique properarent, ille nutricius, depositis clypeo et galea et lorica, pannis dumtaxat usualibus circumtectus, sola lancea et gladio comitatus, morti in prima acie se obiecit, ne alumni et gentis excidii esset trestis ».

${ }_{71}$ Ibid., p. 150a : «Erant autem cum eo [Rege Adefonso] tres fratres, viri nobiles et fideles, videlicet Petrus Assurii, Gundisalvus Assurii, et Fernandus Assurii, quos Urraca Regina fratris sui Regis Adefonsi custodiae et consilio deputarat ».

72 Ibid., p. 147a : « [...] munitiones plurimas regni Castellae, Castellanis omissis, Aragonensium fidei commendavit, quas eorum aliqui diu fideliter tenuerunt ».

${ }^{73}$ Ibid., p. 148a : «Tunc celebrata curia, terram petiit ab omnibus Castellanis, quam tamen à Rege Aragoniae tunc tenebant. Sed ut fidelitatis debitum exposcebat, terram quam tenebant, ei communiter reddiderunt ».

${ }_{74}$ Ibid., p. 160b-161a: « His decertationibus inflammati, terram Regis pueri cum deberent fideliter regere, et tueri, incursionibus et cladibus affecerunt, et crescentibus malis, usque adeo res processit, ut Regi Legionensi fere totius regni, et etiam Toleti per duodecim annos solverentur reditus et tributa, et Comes Amalaricus ad tantae necessitatis articulum fuit ductus, ut Regi Legionensi facere hominium cogeretur de dando Rege pueri in vassallum. Cumque cum ipso Rege Soriam pervenisset, ut iuxta hominium Regem puerum reciperet in vasallum, facto Concilio Soriensi, illi quorum fidei Rex tenellus fuerta deputatus, Amalarico Comiti sic dixerunt : 'Liberum vobis damus, et liberum custodite'. Et tunc puer à quopiam concitatus, in brachiis baiuli coepit flere, et in domum ducitur sub specie cibi dandi, ut sic à fletu cessaret, et patruo traderetur. Tunc Petrus Nunii de fonte Almexiri, miles strenuus et fidelis, Regem puerum protexit sub cappa, et velocissimo equo insidens, ea die ad castrum Sancti Stephani duxit eum ». Bilans : p. 162a : «[...] munitiones plurimas immerito perditas merito recuperavit, faventibus sibi Amalarico et Nunio Comitibus, et plurimis magnatibus, qui toto tempore vitae suae ei inseparabiliter et fideliter adhaeserunt » ; p. 163a : « [...] suorum fidelitate et industria recuperavit perdita »; p. 168 a : « Licet igitur fidelitate suorum regni perdita reparasset, tamen semper fuit à patruo infestatus ».

75 Ibid., p. 193b : «Sed praedicti magnates tamquam naturali dominae fideliter adhaerentes, Regi parvo fidelitatis debitum in omnibus servaverunt ». 
après la mort $\mathrm{d}^{\prime} \mathrm{Henri}^{76}$. Ici aussi, une formule se répète, qui caractérise certains par cette association de termes qui voudrait valoir une équivalence: «nobilis et fidelis $»^{77}$. Et comme dans le cas de la «largitas» royale, toujours à l'occasion du règne d'Alphonse VIII de Castille, Rodrigue consacre tout un chapitre à l'éloge de la «fidelitas » et à sa racine de nature sprituelle, la «fides», comme valeurs fondamentales sur lesquelles repose l'ordre politique et social :

«Quoi de plus glorieux que la foi ? Sans foi, impossible de plaire à Dieu. $\mathrm{Si}$, comme les théologiens l'affirment, la foi est la première grâce par laquelle justice est rendue à l'impie, par elle I'homme damné retrouve la grâce. Quoi de plus désirable que la fidélité ? Comme elle est utile et honnête, Dieu, qui peut tout, n'a pas voulu que le monde fût gouverné sans elle, car si elle venait à disparaître, I'homme ne se soumettrait pas à I'homme, nul ne serait sûr d'autrui et il n'y aurait pas de commerce entre les hommes; au contraire, personne ne se suffisant à luimême, ce serait la fin de la société humaine et ainsi toute chose aurait été faite en vain $\gg^{78}$.

Quant à nous, retenons d'abord ceci : dans trois des exemples où la fidélité s'illustre, Rodrigue invoque un « fidelitatis debitum $»^{79}$. Sur quoi repose cette «obligation» de fidélité ? Est-elle ancrée dans quelque réalité de l'ordre du droit ?

\section{« Dominium naturale » et « hominium 》}

Toutes les sollicitations explicites du « fidelitatis debitum » se font -en deux occasions sur trois, expressément- en référence à l'autorité du

\footnotetext{
${ }^{76}$ Ibid., p. 196a : «Cum autem audisset Regina potiores extremorum Dorii et de ultra Serram Secobiae convenire, misit nuncios qui eis fidelitatis debitum suaderent. Cumque viri extremorum Dorii hoc audissent, venire ad Reginam nobilem continuo consenserunt, et cum ad Vallem oleti communiter convenissent, ibidem tam extremorum Dorii potiores qui pro omnibus venerant, quam etiam magnates et milites Castellani communi consensu regnum Castellae fidelitate debita Reginae nobili obtulerunt ».

${ }_{77}^{7 b i d ., ~ p . ~ 115 b, ~ 150 a, ~ p a s s i m . ~}$

${ }^{78}$ Ibid., p. 162b : «Quid fide gloriosius ? Impossibile est enim Deo placere quempiam sine fide. Si prima gratia in justificatione impii fides à Theologis praedicatur, per hanc damnatus homo gratiae redonatur. Quid fidelitate potius appetendum ? Cum enim sit utilis et honesta, sine hac Deus qui omnia potest, noluit mundum regi, quia si haec periret, homo homini non subesset, nec quisquam ab alio tutus esset, et convictus inter homines non adesset, sed nec quisquam sufficeret sibi solus, et ita congregatio hominum deperiret : igitur cuncta nihilo facta essent $\gg$.

${ }^{79}$ Ibid., p. 148a, 193b, 196a.
} 
« dominus naturalis »: Iorsque après le divorce d'Alphonse le Batailleur et d'Urraque, les tenants castillans nommés par le roi d'Aragon restituent leurs places fortes à la reine de Castille $^{80}$, lorsque, confrontés à I'inconduite des tuteurs du jeune Henri Ier, les Haro et leurs amis serrent les rangs autour de la régente, sa sœur aînée Bérengère ${ }^{81}$, lorsque, après la mort d'Henri, Bérengère s'emploie à ce que les hommes de I'Estrémadure reconnaissent son autoritée ${ }^{82}$. Au-delà de la stricte lexicalisation du «fidelitatis debitum», la «fidelitas » est souvent invoquée dans le cadre, ici encore nommément établi, du rapport au « dominus naturalis ». Ainsi, plutôt que d'ériger, en la personne de Pierre Atarès, « un noble » en roi, Pierre Tizón et Pèlerin de Castillo Azuelo préfèrent œuvrer à ce que Ramire le Moine, frère du roi d'Aragon mort sans progéniture, rompe la clôture du couvent et monte sur le trône, afin que soit préservée la «fidelitas naturali domino $»^{83}$. L'on voit, du reste, le principe du «naturale dominium » invalider les notions de «fidelitas » et de «proditio » lorsque celles-ci tiennent à d'autres engagements. Au temps de la chaotique minorité d'Alphonse VIII, les Lara ont réussi à soustraire le roi à l'étroite surveillance de son oncle Ferdinand II de León. S'étant néanmoins engagés à restituer l'enfant, ils feignent de partir à sa recherche mais ne tiennent pas leur parole. Voici ce qu'écrit à ce propos Rodrigue :

«Quand le roi Ferdinand l'apprit, il s'en affligea, considérant qu'il avait été abusé, et il envoya un chevalier au comte Amalric pour lui reprocher son infidélité («infidelitas ») et son parjure («periurium »). Mais comme celui-ci faisait tout son possible pour libérer son seigneur naturel («dominus naturalis») et plaçait son tendre seigneur au-dessus de toute chose, le messager venu demander des comptes fut renvoyé au milieu des moqueries et sans réponse aucune. Finalement, lorsque le roi Ferdinand accusa le comte Amalric en sa présence, on dit

${ }^{80}$ Ibid., p. 148a : « Sed ut fidelitatis debitum exposcebat, terram quam tenebant, ei communiter reddiderunt. [...] munitiones et castra omnia quae tenebant, Reginae naturali dominae reddiderunt $\gg$.

${ }^{81}$ Ibid., p. 193b (voir extrait note 75).

${ }^{82}$ Cf. note 76.

${ }^{83} D R H$, p. 118a : « Unde et quemdan nobilem qui dicebatur Petrus Tarasiae, volebant Regi mortuo subrogare [...] [Sed] duo magnates, scilicet Petrus Titionis de Catherecta, et Peregrinus de castello Acioli, cum essent nobiles et potentes, et vellent fidelitatem naturali domino custodire, plurimorum animos à primo proposito revocarunt, et ut Ranimirum monachum à monasterio evocarent, vigilanti studio procurarunt ». 
que le comte lui répondit ceci : 'Si je suis fidèle («fidelis»), traître («proditor») ou félon (« alevosus »), je l'ignore ; mais, autant que j'ai pu, j'ai libéré mon tendre et jeune seigneur d'une servitude indue, puisque je suis sous sa seigneurie naturelle (« cum sim eius dominii naturalis »)».

Et Rodrigue ajoute : «À ces mots, tous s'accordèrent à le disculper de l'accusation portée contre lui $\gg^{84}$.

Le Tolédan semble donc gagné au principe de la «seigneurie naturelle » sur lequel repose, au XIIIe siècle, le renforcement du pouvoir royal et les prémices doctrinales de l'État en Castille : une conception du pouvoir politique selon laquelle l'ensemble des hommes nés ou vivant depuis longtemps sur un territoire doivent «amour», « respect» et « obéissance » au seigneur qui légitimement le gouverne ${ }^{85}$. Dans la vision historique de Rodrigue les notions de «dominus naturalis» et de « dominium naturale » ne sont pas très anciennes et semblent concerner surtout l'espace navarro-aragonais et castillan. Elles n'apparaissent ni au temps de la royauté asturienne ni sous les rois de León ${ }^{86}$. Une première invocation du « debitum naturale » a lieu sous le règne de Garsias III de Navarre, à la veille de la bataille d'Atapuerca, qui se déroula en $1054^{87}$. La notion de «dominus (ou de «domina ») naturalis » est ensuite sollicitée quatre fois au début du XIIe siècle. Elle concerne trois fois la reine Urraque de Castille, femme du Batailleur ${ }^{88}$, une fois Ramire le Moine, roi

\footnotetext{
${ }^{84}$ Ibid., p. 161a-b : «Quod audiens Rex Fernandus, doluit, reputans se delusum, et misit quemdam militem Comiti Amalrico, qui eum de infidelitate et periurio appellaret. Qui attendens pro liberatione domini naturalis quidlibet faciendum, et tenellum dominum omnibus praeponendum, nuncium qui ad reptandum venerat, iocose delusum, sine responso alio remiserunt. Tandem cum Rex Ferdinandus Comitem Amalricum praesentialiter reptaret, Comes Amalaricus sic dicitur respondisse : 'Si sum fidelis, aut proditor, aut alevosus, nescio ; sed qocumque modo potui, tenellum puerum dominum meum à servitute indebita liberavi, cum sim eius dominii naturalis'. Ad haec omnium iudicio est ab imposito crimine absolutus ».

${ }^{85}$ Sept parties, notamment, II, i-xx et IV, xxiv.

${ }^{86}$ La première référence à la seigneurie naturelle dans I'histoire que fait Rodrigue du royaume de León survient lors de la prise de pouvoir de Ferdinand III de Castille, quand celui-ci est reconnu comme «seigneur naturel » par les chevaliers de Toro $\left(D R H_{.}, \mathrm{p}\right.$. 203b). Cf. note 111.

${ }^{87} D R H$, p. 124b : « Tunc duo milites quorum bona proscripserat, naturale debitum abnegantes, se in adversarium transtulerunt ».

${ }^{88}$ Ibid., p. 148a ( $c f$. note 79 ) ; voir également la restitution de ses honneurs par Pierre Ansurez, note 101 : «Terram quam mihi dedistis, Reginae restitui cuius erat, meae dominae naturali », «In crastino autem magnates sui in consilio suaserunt, ut tali Principi qui fidelitatem naturali dominae sic servaverat... » (ibid., p. 148a-b).
} 
d'Aragon ${ }^{89}$. Elle apparaît enfin sous le règne d'Alphonse VIII (une occurrence ${ }^{90}$ ) puis, à cinq reprises, $c^{\prime}$ est-à-dire avec une fréquence proche de la somme de toutes les autres occurrences, au long de la vie de Bérengère et des rois qu'elle accompagne, Henri Ier et Ferdinand $\mathrm{III}^{91}$. La majorité des occurrences (6 sur 11) marque donc l'époque de Rodrigue. L'usage de cette notion, en effet, pourrait n'être pas ancien en Castille en ce début des années 1240 où est composé le De rebus. Le «señor natural » trouvera sa pleine définition juridique dans les Sept parties d'Alphonse $X$ le Sage, dont la première rédaction commence en 1256 et s'achève en 1265 , mais on se réfère tout de même abondamment à cette notion dans le Cantar de Mio Cid, composé vers 1200. Les premiers emplois courants pourraient donc dater de la fin du XIIe siècle ou du début du XIIIe ${ }^{92}$. Rodrigue les ferait alors remonter tendancieusement au début du XIIe siècle, voire au XIe. C'est dire tout à la fois l'actualité de l'enjeu réel que constitue la «seigneurie naturelle » et l'importance qu'elle revêt aux yeux de notre historien, dont le récit présente, sans jamais la justifier, la contrainte qu'elle induit comme irrévocable.

Le «naturale debitum», cependant, n'épuise pas à lui seul le «fidelitatis debitum ». La «fidelitas » est également due au sein d'un autre rapport politique qui engage plus librement la personne et sa « fides » et qui se contracte par I' « hominium », le plus souvent - « prout exigit mos Hispanus » écrit Rodrigue ${ }^{93}$ - par un baisemain, que ce rite institue une authentique relation de «dominus» à «vassalus » ou quelque autre obligation personnelle de moindre portée ${ }^{94}$. Dans le $D e$ rebus, il est rare de voir le principe d'une obligation personnelle

\footnotetext{
${ }^{89} \mathrm{Cf}$. note 83 .

${ }^{90} \mathrm{Cf}$. note 84 .
}

${ }^{91} \mathrm{Cf}$. notes 74, 75, 76 ; $D R H$, p. 197b : «Inde ad urbem Burgensem redeuntes (Regina Berengaria et Enricus Rex), à Pontifice, clero, et populo honorifice et processionaliter sunt recepti, gaudentibus omnibus, quod liberati ab hostibus in dominae naturalis dominio remanserunt »; p. 198a (capture du rebelle Alvare Nuñez de Lara) : « Et qui multos offenderat, qui nulli pepercerat, qui naturali dominae eius dominium abnegarat, divino iudicio nunc prostratus, suorum militum et fratrum intuentium auxilio destitutus, capitur inglorius et confusus $\gg ;$ p. 203b : (remise de la forteresse de Toro au jeune Ferdinand III) « [...] ex Tauro, nobilissimo oppido, milites advenerunt, qui Regem sui et oppidi naturalem dominum cognoverunt $\gg$.

${ }^{22}$ Quelques repères chronologiques supplémentaires dans Georges MARTIN, « Alphonse $X$ ou la science politique (Septénaire, 1-11)», [deuxième partie : "Le modèle politique"], Cahiers de linguistique hispanique médiévale, 20, 1995, p. 7-33 (p. 21-27).

${ }^{93} D R H$, p. 115 b : « ei obviam occurrentes, manus osculo (prout exigit mos Hispanus) se ieus dominio subiecerunt, quorum hominium iam securus... »

${ }_{94}$ Le vasselage existe cependant au sens strict : ibid., p. 153b, 160b, 198b (cf. notes 95,98 et 105). 
contractée par I'« hominium » concurrencer le « debitum naturale ». Le vasselage, et plus largement I' « hominium», engagent le plus souvent deux rois ou un roi et un prince, et donc deux personnes grossièrement de même rang qui n'appartiennent pas au même territoire : Ramire le Moine, roi d'Aragon et le roi « des Espagnes » Alphonse VII ${ }^{95}$, Ben Ganiya de Cordoue et ce même Alphonse $\mathrm{VII}^{96}$, Ferdinand II de León et Sanche III de Castille, virtuellement ${ }^{97}$, Alphonse VIII de Castille enfant et le roi de León Ferdinand $\mathrm{II}^{98}$. L' « hominium » peut aussi lier deux personnes dont les territoires sur lesquels elles ont autorité sont sur le point de se séparer et qui formalisent ainsi une prise de distance relativement au régime du «dominium naturale », la personnne dépendante étant alors portée au «principatus». C'est le cas du comte Henri de Portugal et de son beau-père Alphonse VI de Castille ${ }^{99}$.

Il arrive néanmoins dans le De rebus que I' « hommage », et même le «vasselage » quelquefois contracté à travers lui, lient à un roi un membre de la noblesse. C'est, du reste, dans ce cadre que l'on trouve le seul exemple d'une confrontation des obligations nées de l'« hominium » avec le « debitum naturale». Le cas est unique, mais Rodrigue lui donne le relief le plus vif. Nous sommes au temps des rapports matrimoniaux tempétueux d'Urraque de Castille et d'Alphonse Ier d'Aragon. De I'Aragonais, le comte Pierre Ansurez a reçu en Castille des terres au titre $\mathrm{d}^{\prime}$ " honores», bien royaux incessibles et habituellement intransmissibles, pour lesquels il a rendu au roi $\mathrm{I}^{\prime}$ " hommage de main et

95 Ibid., p. 153b : « Tandem post longa certamina ea lege in concordiam redierunt, ut Rex Aragonum omnia supradicta teneret in feudo à Rege Hispaniarum, et ei fieret in vasallum. Quod et fuit fideliter observatum usque ad obsidionem Conchae, in qua dicitur Rex Castellae Aldefonsus nobilis Regi Aragonum Aldefonso hominium et dominium remisisse 》

${ }_{96}$ Ibid., p. 154b : «[...] Avengamiae qui ei civitatem dederat, commisit custodiam civitatis, et ille super librum Mahometi qui Alchoranus dicitur, sibi et Regi Sancio filio suo fecit hominium, et iuravit ».

${ }_{97}$ Ibid., p. 157b : (Ferdinand s'adresse à son frère Sanche) «'Ad vos tanquam ad patrem et dominum veni securus, de virtute bona praesumens, et supplico quod regni mei fines invadere non velitis, quia etiam si velletis, vobis hominium facere sum paratus'. Cui Rex Sancius sic respondit: «Absit à me, ut terram quam pater meus vobis contulit, meae subiiciam potestati, vel frater meus, filius tanti patris, alicui hominio sit astrictus... »

${ }_{98}$ Ibid., p. 160b : « [...] Comes Amalaricus ad tantae necessitatis articulum fuit ductus, ut Regi Legionensi facere hominium cogeretur de dando Rege puero in vassallum ».

${ }^{99}$ Ibid., p. 151b : « Verum Comes Enricus de quo diximus quod Rex Aldefonsus Tarasiam filiam ei dederat in uxorem, cum esset vir bonus, iustus, strenuus, timens Deum, coepit aliquantulum rebellare, non tamen subtraxit hominium toto tempore vitae suae ; sed à finibus Portugalliae eiecit, prout potuit, Agarenos, sibi iam specialem vendicans principatum ». 
de bouche » («manu et ore hominium »). Mais voici qu'à la suite de la séparation des époux, la reine Urraque, «seigneur naturel » des Castillans, réclame ses terres. Voyons alors agir Pierre Ansurez :

«Le comte Pierre Ansurez, vêtu d'écarlate et monté sur un cheval blanc, tenant dans sa main une corde, se rendit en personne («personaliter») au château appelé Castellar auprès du roi des Aragonais auquel il avait rendu hommage de main et de bouche pour la terre qu'il avait reçue de lui au titre d'honneur, et il déclara devant toute la cour: 'La terre que vous m'avez donnée, je l'ai rendue à la reine, mon seigneur naturel, à qui elle appartenait. Quant aux mains, à la bouche et au corps qui vous ont fait hommage, je vous les offre pour qu'ils reçoivent la mort ou tout autre supplice' $\gg$.

Le commentaire vient du noble entourage du Batailleur :

« Le lendemain, ses magnats persuadèrent [le roi] en conseil de pardonner généreusement («liberaliter») à ce prince qui avait si bien gardé la fidélité à son seigneur naturel et qui offrait au supplice son corps et ses membres. Il avait en effet observé la fidélité due à l'un et à l'autre de ses seigneurs, comme l'exigeait I'obligation de la seigneurie (« dominii debitum ») ${ }^{100}$.

Ce dénouement exemplaire du conflit auquel est soumis Pierre Ansurez - «les Espagnols imitent encore ce fait aujourd'hui » souligne à cette occasion Rodrigue ${ }^{101}$-, proclame d'abord la primauté et l'intangibilité absolues du «dominium naturale». Nulle hésitation, nul retard dans l'observation de ce «debitum »: Pierre Ansurez rend immédiatement la

100 Ibid., p. 148a-b : « Tunc Comes Petrus Assurii, indutus scarlato, et insidens equo albo, et portans funem in manu, accessit personaliter ad Regem Aragonum in castro quod dicitur Castellare, cui manu et ore hominium fecerat pro terra quam ab eo acceperat in honorem, in plena curia sic proponens: 'Terram quam mihi dedistis, Reginae restitui, cuius erat, meae dominae naturali. Manus autem, os, et corpus, quae fecerunt hominium, vobis offero morte vel dispendio consumenda'. Tunc Rex cum esset aliquantulum iracundus, voluit in continenti sententialiter condemnare, sed suasus à suis, sententiam distulit promulgare. In crastino autem magnates sui in consilio suaserunt, ut tali Principi qui fidelitatem naturali dominae sic servaverat, et ei corpus et membra ad dispendium offerebat, liberaliter indulgeret : fidelitatem enim utrique domino observarat, prout dominii debitum exposcebat. Et insontem remisit cum muneribus et honore, cuius factum Hispani adhuc hodie imitantur »

${ }^{101}$ Ibid., p. 148b : « [...] cuius factum Hispani adhuc hodie imitantur ». 
terre à sa «naturalis domina ». Pour l'autre « debitum », celui tenant à $I^{\prime}$ « hominium », on le respecte aussi et strictement, mais en second lieu, dans la situation créée par le respect du premier: Pierre met sa personne, c'est-à-dire son corps, à la merci du «dominus » étranger à qui il a rendu l'hommage. À ce dernier de voir. La mort, le supplice, mais aussi le pardon, l'arrangement, la récompense même sont possibles ${ }^{102}$.

Si I'on s'en tenait à cela, il faudrait conclure que, pour Rodrigue Jimenez de Rada, le rapport politique de la noblesse avec la royauté obéit à un système à trois niveaux. Au plan d'une économie matérielle de la société politique, un échange de biens et de services (la «terra » et son «proventus» contre I'« auxilium» et le « consilium »); au plan d'une éthique politique, une correspondance entre la «largitas» royale et la «fidelitas » nobiliaire; au plan juridique, enfin, et dans les limites du royaume, le «dominium naturale » et le «debitum » qu'il induit. Pourtant, la vignette exemplaire élaborée autour du comte Pierre Ansurez dit aussi au lecteur qu'un «dominii debitum » existe qui peut subsumer le «naturale debitum » et le «fidelitatis debitum» créé par $I^{\prime}$ « hominium», lesquels, s'ils impliquent en l'occurrence des entités différentes, la «terre » ou la personne, doivent néanmoins être respectés tout aussi «fideliter ». Certes, I' « exemplum » de Pierre Ansurez s'ajuste à la partition qui fait correspondre deux régimes juridiques de la fidélité nobiliaire à deux configurations spatiales de la dépendance : d'un côté la fidélité due à la reine en tant que seigneur naturel du royaume; d'un autre côté la fidélité due au roi en tant que seigneur personnel, qui s'exerce dans un rapport interterritorial. Mais n'arrive-t-il pas que ces deux régimes coïncident dans le même homme et sur le même territoire ?

Ce cas est en réalité assez fréquent dans le De rebus Hispaniae. Son expression, toutefois, est souvent implicite et l'on ne sait alors si le comportement du noble est requis par une «fidelitas» due à l'obligation personnelle ou, plus probablement à mon sens, par la primauté absolue du « debitum naturale ». Sanche III peut ainsi exiger de ses magnats qu'à sa mort ils restituent à son successeur les terres qu'ils tiennent de lui en « feudum temporale $»^{103}$ et Ferrand Ruiz de Castro « le Castillan »,

\footnotetext{
${ }^{102}$ C'est du reste cette dernière éventualité qui couronne heureusement l'épisode : « Et insontem [Rex] remisit cum muneribus et honore » (ibid, p. 148b)

${ }^{103}$ Ibid., p. 159b : «Cum desiderabilis Sancius pater eius videret diem obitus imminere, vocatis magnatibus, mandavit omnibus, ut terrarum dominia quae ab eo tenebant, feudo temporali usque ad annos quindecim retinerent, e tunc filio suo fideliter resignarent. »,
} 
partant joindre ses forces à celles des «Agaréens » remet préalablement à Alphonse VIII de Castille les «feuda » qu'il avait reçus de lui ${ }^{104}$. Si la mention de «feuda» peut faire songer à l'établissement d'un engagement personnel, probablement vassalique, auprès du monarque, on a toutefois le sentiment que, semblablement à ce qui s'opérait dans le cas de Pierre Ansurez, c'est surtout en tant que « dominus naturalis » que le roi récupère ses terres.

Il arrive cependant que l'acquisition d'une dépendance personnelle -le vasselage, notamment- prenne une importance particulière en ce qu'elle constitue une solution juridique aux relations difficiles du roi avec un noble dans le cadre du «dominium naturale » et donc qu'elle compense l'affaiblissement de ce régime ou même qu'elle se substitue à lui. Au début du règne de Ferdinand III, dont on connaît les péripéties, le comte rebelle Ferrand Nuñez de Lara accepte de se soumettre au roi et de lui rendre les forteresses où il résiste «à la condition de devenir son vassal et de tenir de lui ces châteaux en qualité de vassal personnel (« vasallus proprius $\gg) \gg^{105}$. Nous trouvons un autre raccommodage du «dominium naturale» dans I' «hominium» fait à l'infant Garsias par le lignage castillan des Vela, lequel, presque autant que celui rendu par Pierre Ansurez, montre la très grande force du «fidelitatis debitum » contracté dans I' « hominium ». Si l'opprobre retombant sur les assassins va être si grand, si, du reste, Garsias et ses compagnons vont été pris au dépourvu, c'est que I'hommage rendu par les Vela donne au premier comme aux seconds le sentiment d'une absolue sécurité, au point que la fiancée, qui s'ouvre pourtant aux magnats castillans des rumeurs d'une trahison, ne les voit pas prêter foi à sa mise en garde ${ }^{106}$.

${ }^{104}$ Ibid., p.164 a-b : «Erat auteù tunc temporis vir nobilis, de quo diximus, ex Castella, Fernandus Roderici, agnomine Castellanus, qui postquam feuda quae tenebat, Regi restituerat Castellano, recesserat à Castella, et transivit ad Agarenos [...] »

105 Ibid., p. 198b : « Rex autem duxit exercitum versus Castrum, et licet Comes Fernandus fultus copia victualium et multitudine armatorum inibi rebellaret, ea conditione restituit Castrum et Orzeionem, ut eius vasallus fieret, et $a b$ eo ut vasallus proprius castra teneret $\gg$.

${ }^{106}$ Ibid., p. 115b : «Erant autem tunc temporis Legione filii Vegilae Comitis, Rodericus Vegilae, Didacus Vegilae, et Enechus Vegilae, qui ob patris odium proditionis anheli in filium congesserant factionem, et ei obviam occurrentes, manus osculo (prout exigit mos Hispanus) se ieus dominio subiecerunt, quorum hominium iam securus, et paranymphis dulci alloquio persuasis, permissus est Infans optatis solatiis delectari. [...] Tunc quidam milites de regno Legionis cum praedictis filiis Vegilae ad Sarracenos transfugae, eo quod à Comite Sancio indignanter recesserant à Castella, proditione tractata, Infantem Garsiam annorum tredecim occiderunt, Roderico Vegilae ea manu, qua eum de sacro fonte levaverat, gladio feriente. Et proditionem huiusmodi sponsa sua Sancia quae utcumque perceperat, revelarat; sed magnates qui secum aderant, cum essent nobiles et fideles, tantum facinus credere noluerunt ». 
Mais le De rebus offre bien d'autres cas d' « hominia » scellés au sein du « dominium naturale » dont la perspective qu'ils ouvrent est à la fois plus vaste et plus actuelle. Rodrigue, en effet, ne feint pas d'ignorer que I'histoire des royautés d'Espagne n'est pas un long fleuve tranquille. Il montre volontiers comment des circonstances défavorables -minorités et ruptures généalogiques, notamment- peuvent faire que les principes les mieux établis soient brouillés ou menacés. $L^{\prime}$ « hominium » peut alors étayer le «debitum naturale » et même s'insinuer en lui au point de le remplir de sa propre «fides», de sa propre «fidelitas». C'est en échange d'un serment et d'un hommage solennels de ne pas usurper les prérogatives royales, faits, du reste, à Rodrigue lui-même, que Bérengère abandonne son jeune frère Henri Ier à la tutelle des Lara ${ }^{107}$. C'est à travers serments et hommages qu'à la mort d'Henri Ier sont reconnus en Castille Bérengère puis son fils Ferdinand III, dans le cadre, pourtant, de ce qui est présenté par Rodrigue comme un «fidelitatis debitum » antérieur, dû implicitement au titre du «naturale debitum $»^{108}$. Et c'est à travers serments et hommages qu'à la mort d'Alphonse IX de León, sous le regard, encore, de notre archevêque, les Léonais « reconnaissent » son fils Ferdinand III comme «seigneur naturel » : serment des évêques, des magnats et des villes ${ }^{109}$, reconnaissance et hommage des chevaliers de la

107 Ibid., p. 193a : «Quod cum sollers Regina Berengaria percepisset, animo gratanti concessit; sed timens insolentias quae venerunt, fecit iurare Comitem Alvarum et magnates, ut sine ipsius Reginae consilio, nec aliquibus terram auferrent, nec aliquibus terram darent, nec vicinis Regibus guerram moverent, nec mulctam, quae Hispaniae pecta dicitur, imponerent in aliqua regni parte : et iuramento et hominio in manu Roderici Toletani Pontificis firmaverunt, et si contrarium facerent, proditionis infamia tenerentur $\gg$.

${ }^{108}$ Ibid., p. 196a : «Cum autem audisset Regina potiores extremorum Dorii et de ultra Serram Secobiae convenire, misit nuncios qui eis fidelitatis debitum suaderent. Cumque viri extremorum Dorii hoc audissent, venire ad Reginam nobilem continuo consenserunt, et cum ad Vallem oleti communiter convenissent, ibidem tam extremorum Dorii potiores qui pro omnibus venerant, quam etiam magnates et milites Castellani communi consensu regnum Castellae fidelitate debita Reginae nobili obtulerunt. Ipsi enim, decedentibus filiis, cum esset inter filias primogenita, regni successio debebatur, et hoc ipsum patris privilegio probabatur, quod in armario Burgensis Ecclesie servabatur, et etiam totum regnum antequam Rex haberet filium, bis iuramento et hominio hoc firmarat» (p. 196a-b) ; puis : « et ibidem filio regnum tradens, Infans Fernandus de quo diximus, omnibus approbantibus, ad Ecclesiam Sanctae Mariae ducitur, et ibidem ad regni solium sublimatur, anno aetatis suae decimo octavo, clero et populo decantantibus, Te laudamus, te Dominum confitemur. Et ibidem omnes ei fecerunt hominium, et fidelitatem Regi debitam iuraverunt, et sic honore regio ad regale palatium est reductus ».

${ }^{109}$ Ibid., p. 203b : «Propter quod mater eius Regina nobilis domina Berengaria ad eum materna sollicitudine veniebat, ut ad recipiendum regnum paternum quantocius festinaret, quod ei de mandato patris Pontifices, magnates, et civitatum concilia iurarant, ne forte in mora perturbatio aliqua oriretur ». Le narrateur est ici un « nous » 
place forte de Toro ${ }^{110}$, sans compter le « don » de soi que font au roi les évêques et leurs cités ${ }^{11}$.

C'est peu dire que ces événements récents, dont Rodrigue Jimenez de Rada a souvent été le témoin direct et dans lesquels il a parfois joué un rôle de premier plan, ont laissé leur trace vive dans l'esprit de l'historien. Nous sommes, au moment de la rédaction du De rebus, non loin, quoique encore à plus de dix ans, de la composition des Sept parties, code royal où va triompher le principe du « señorío natural » et de la «naturaleza » mais qui, en grande partie à cause de cette bruyante proclamation, ne sera guère appliqué avant les années centrales du XIVe siècle et encore au titre de droit supplétif ou de recours. Rodrigue est un homme de la noblesse et un homme de son temps, même s'il est aussi un grand serviteur de la royauté. Il est en outre un être doté d'une grande intelligence, d'une grande culture et d'une grande expérience du politique. Sa formation à Bologne peut-être, et sans doute son imprégnation par ce qui germe dans l'entourage de Ferdinand III ou de Bérengère d'une doctrine dont l'éclosion aura lieu sous le règne d'Alphonse $X$, indiquent à Rodrigue et le poussent à déclarer que l'ordre royal va vers une forme d'organisation dont le «dominium naturale » sera la pierre de touche institutionnelle ${ }^{112}$. Mais Rodrigue sait aussi qu'au

qui inclut l'auteur («Altera vero die Taurum intravimus... »). C'est que « erant autem cum [Rege] Rodericus Pontifex Toletanus, Lupus Didaci, Alvarus Petri, Gonsalvus Roderici, Garsias Fernandi, Alfonsus Tellii, Guillermus Gonsalvi, Didacus Martini, et alii nobiles, et magnates, et plures milites civitatum, qui cum Rege inclito venientes, Reginam nobilem in pago qui Orgatium dicitur, invenerunt, et inde communiter urbem regiam intraverunt, etc. »

${ }^{110}$ Ibid., p. 203b : «Sequenti die eum similiter in villa Lalii receperunt, ubi ad Regem, tamquam ad dominum, ex Tauro, nobilissimo oppido, milites advenerunt, qui Regem sui et oppidi naturalem dominum cognoverunt, et, ut sequenti die Taurum adiret, instantissime supplicarunt, nobili Regina haec omnia procurante. Altera vero die Taurum intravimus, ubi omnibus annuentibus, Rex Fernandus, facto sibi hominio, in Regem et dominum est receptus ».

${ }^{111}$ Ibid., p. 204b : «Sed tamen regni Praelati, quorum interest regnum et sacerdotium contueri, in auditu auris Regem Ferdandum in Regem illico receperunt, scilicet, Ioannes Ovetensis, Nunius Astoricensis, Rodericus Legionensis, Michael Lucensis, Martinus Salamantinus, Martinus Mindonensis, Michael Civitatensis, Sancius Cauriensis. Hi omnes cum suis civitatibus, patre mortuo, filio se dederunt, nec rebellio cogitata potuit invalere ». Sur le caractère exceptionnel de ces pratiques, Hilda GRASSOTTI, LaS instituciones feudo-vasalláticas en León y Castilla, 2 vol., Spolète : Centro italiano di studi sull'alto medioevo (4), 1969, 1, p. 208-210. Une interprétation intéressante dans José Manuel NIETO SORIA, «La monarquía fundacional de Fernando III », in :Fernando III y su tiempo (1201-1252, VII congreso de estudios medievales de la fundación Sánchez-Albornoz, León (sous presse). Je remercie l'auteur de m'avoir fait l'amitié de pouvoir lire son travail avant publication.

${ }_{112}$ L'émergence, ou en tout cas la consolidation, du concept de «dominium naturale » fut, à mon sens, un des éléments fondamentaux de ce qui, selon José Manuel NIETO 
présent cette obligation s'accompagne encore et même est encore toute pénétrée de «fides» et de «fidelitas » personnelles ${ }^{113}$. Nous avons vu I'auteur du De rebus se mettre lui-même en scène pour recevoir, au bénéfice de la royauté castillane, l'hommage et le serment des Lara s'apprêtant à prendre en charge la tutelle du jeune Henri Ier. La documentation garde trace de deux inféodations scellées par un « hominium » d'entrée en vasselage rendu au Tolédan autour de 1220 et dont on a tout lieu de croire qu'elles ne sont pas étrangères au souci de la royauté castillane de préserver son influence sur les seigneuries des confins orientaux du diocèse de Tolède ${ }^{114}$. Alors : «dominium naturale » et « debitum » correspondant, soit. Mais s'il veut se gagner et conserver la «fidelitas» de la noblesse, son « animus», son « amor», le roi, à qui, en toute première instance, s'adresse Rodrigue, doit dans l'immédiat

SORIA, se préparait à la cour de Ferdinand III de la future législation alphonsine (« La monarquía fundacional... »).

${ }^{113}$ Sur le rayonnement de la «fides » dans la conceptualisation politique du De rebus Hispaniae, voir Georges MARTIN, Les Juges de Castille... p. 264-266.

${ }^{114}$ Les documents en question ont d'abord été publiés et étudiés par Claudio SÁNCHEZ ALBORNOZ, «El Juicio del libro en León durante el siglo $X$ y un feudo castellano del siglo XIII », Anuario de historia del derecho español, 1, 1924, p. 387-390 et par Ramón de PAZ, « Un nuevo feudo castellano», Anuario de historia del derecho español, 5, 1928 , p. 445-448. Ils ont été ensuite rapidement commentés par Hilda GRASSOTTI dans Las instituciones feudo-vasalláticas en León y Castilla, 2 vol., Spolète : Centro italiano di studi sull'alto medioevo (4), 1969, 1, p. 181-182 (édition des documents en note) et 2, p. 626-628. En voici quelques fragments (seigneuries d'Albarracín puis de Molina): «Ego E. Garsie confiteor predictorum castrorum donationem, sicut prescriptum est, recepisse espondens, et firmiter nomine meo et successorum meorum promittens nos supradicta omnia seruaturos, et super hoc ei in presencia tocius capituli sui hominium manuale facio. Adiciens intuitu Dei et anime mee et parentum meorum me esse uassallum suum et ecclesie toletane. [...] Ad hec Ego E. domino R. Archiepiscopo Toletano et successoribus suis nomine meo et successorum meorum hominium facio, et dominio recognosco »; «[...] ita uidelicet quod ego et heredes mei, descendentes a me resta linea, a uobis uel a successoribus uestris, qui pro tempore fuerint, et ab ecclesia toletana uillam Moline, sicut vassalli uestri, in pheudum teneamus, et uobis pro ipsa dominium recognoscamus, et etiam uobis pro ipsa, sicut vassalli uestri, hominium faciamus, ita quod de Molina et termino suos guerram et pacem facere quocienscumque et quandocumque uel placuerit faciatis, etc. ». Plus récemment, Ana RODRÍGUEZ LÓPEZ a consacré plusieurs paragraphes de sa thèse [La consolidación territorial de la monarquía feudal castellana, Madrid : Consejo superior de investigaciones científicas (Biblioteca de historia, 27), 1994, p. 243-254] à l'analyse de ces inféodations. Mon interprétation est contraire à celle d'Ana RODRÍGUEZ, pour qui l'inféodation des seigneurs de Molina et d'Albarracín à Rodrigue de Tolède est un élément de la confrontation de ceux-ci avec la royauté castillane. À mon sens, l'utilité véritable de cette inféodation auprès d'un grand serviteur de la royauté était, pour les seigneurs comme pour le roi (ainsi que pour Rodrigue, sa parenté et le diocèse) d'insérer Molina et certaines forteresses frontalières de la seigneurie d'Albarracín dans le réseau des dépendances de la royauté castillane tout en préservant une forme de liberté pour les seigneurs. En cette affaire comme en d'autres occasions, Rodrigue aura servi astucieusement ses propres intérêts et ceux de la couronne en faisant fonction de pivot entre la noblesse et le roi. 
veiller non seulement à se montrer «hilaris», «modestus » et « affabilis» mais à combler en outre les nobles des bienfaits de sa «largitas ». 